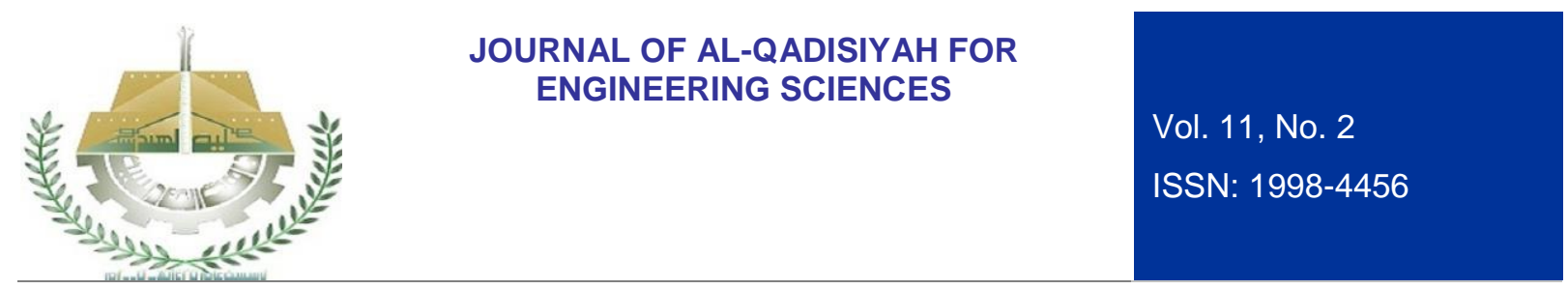

\title{
BROADBAND MICROSTRIP ANTENNA FOR 2G/3G/4G MOBILE BASE STATION APPLICATIONS
}

\author{
Wafaa Mohammed Hashim, \\ College of Engineering, Al-Mustansiryah University, Baghdad, Iraq, Electrical Engineering Department, \\ Email:Wafaa9896a@gmail.com \\ Asst. prof. Dr. Adheed Hasan Sallomi, \\ College of Engineering, Al-Mustansiryah University, Baghdad, Iraq, Electrical Engineering Department, \\ Email: adalameed@yahoo.com
}

\begin{abstract}
In this work, a staircase patch microstrip antenna with slots is proposed to cover the 2G/3G/4G cellular mobile base station bands, when the antenna is excited with a transmission line, creates several modes these modes are composite to obtain a large bandwidth. The proposed antenna operates in the band from $0.86 \mathrm{GHz}$ to $4.78 \mathrm{GHz}$ with an impedance bandwidth of $138 \%$. The use of staircase patch antenna is to achieve more attractive performance such as wider bandwidth, better impedance matching and better radiation. Inserting different slots to the patch of the antenna to enhance the gain and return loss. The gain is obtained ranging from $2.18 \mathrm{dBi}$ to $5.3 \mathrm{dBi}$. Good radiation efficiencies ranging from $70 \%$ to $97 \%$ is achieved.
\end{abstract}

Keywords: 2G/3G/4G mobile base station; broadband microstrip patch antenna; staircase patch; return loss; voltage standing wave ratio.

\section{INTRODUCTION}

The fast growth of mobile communication systems needs both low cost and broadband antenna for base station [1]. Microstrip patch antenna is utilized for its simplicity, low profile, inexpensive to fabricate using modernistic printed circuit technology, conformable to planar and non-planar surfaces. When mounted on rigid surfaces compatible with MMIC (Monolithic Microwave Integrated Circiut) designs became mechanically robust [2]. Main operational abuse of the microstrip antennas are contain low power gain, low efficiency, high quality factor (sometimes in excess of 100), very narrow frequency bandwidth, spurious feed radiation and poor scan performance [3]. A patch antenna is made by excavation metal on one part of dielectric substrate while on the other opposite side there is a metal which constructe a ground plane [4]. There are a great number of forms of microstrip patch antennas, they were designed to match particular characteristics. Some of the common kinds are rectangular, square, and circular patches [5]. Different feeding mechanisms are used to feed the antenna such as coaxial, stripline, aperture coupling or proximity [6].The size of the microstrip patch antenna is inversely commensurate to the operating frequency of the antenna and the bandwidth of the microstrip patch antenna is directly commensurate to the substrate thickness and inversely commensurate to the square root of the dielectric constant of the substrate [7].

\section{STAIRCASE PATCH ANTENNA DESIGN}

The structure of the proposed staircase patch antenna is shown in the Figure (1). The antenna is printed on (FR-4) substrate of thickness $h=1.542 \mathrm{~mm}$ with relative permittivity $\varepsilon_{r}=4.3$, fed by a microstrip feed line. 
The performance of the antenna can be estimated over a sweep frequency range from $0 \mathrm{GHz}$ to $5 \mathrm{GHz}$. The antenna dimensions are $(120 \mathrm{~mm} \times 100 \mathrm{~mm} \times 1.542 \mathrm{~mm})$, and it operates at minimum frequency fmin $=0.86$ $\mathrm{GHz}$ and maximum frequency $f_{\max }=4.67 \mathrm{GHz}$, the center frequency is $f_{0}=2.75 \mathrm{GHz}, \lambda_{0}$ (wavelength of the center frequency) equal to $180.01 \mathrm{~mm}$. Dimensions of the patch are chosen as $w=61.5 \mathrm{~mm}$ represent $0.565 \lambda_{0}, L=46.5 \mathrm{~mm}$ represent $0.258 \lambda_{0}$. The widths of the stairs $\mathrm{W}_{1}, \mathrm{~W}_{2}, \mathrm{~W}_{3}$ equal to $6.5 \mathrm{~mm}, 6.5 \mathrm{~mm}$ and $7.58 \mathrm{~mm}$ respectively and their lengths $\mathrm{H} 1, \mathrm{H} 2$ equal to $2.5 \mathrm{~mm}$.

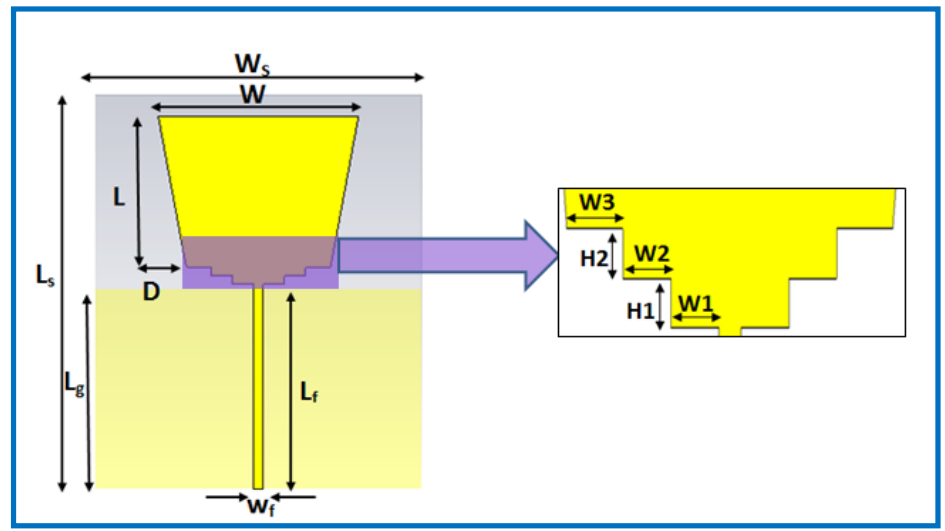

Figure 1. The structure of the proposed staircase patch microstrip antenna.

\section{THE EFFECT OF DIFFERENT ANTENNA PARAMETERS ON ITS PERFORMANCE}

Initial parameters of the proposed antenna give lousy performance, so that changing the antenna parameters and choosing the best values can be done, to improve its performance.

\subsection{THE EFFECT OF GROUND PLAN LENGTH}

Figure (2) shows the S-parameter as a function of frequency for different values of ground plane length $\left(\mathrm{L}_{g}\right)$, and fixing other values at $\mathrm{W}=61.5 \mathrm{~mm}, \mathrm{~L}=46.5 \mathrm{~mm}, \mathrm{~L}_{f}=62 \mathrm{~mm}, \mathrm{~W}_{f}=2.5 \mathrm{~mm}, \mathrm{~W}_{g}=100 \mathrm{~mm}$. From the figure it can be noticed that the curve has good bandwidth with the best return loss at $L_{g}=61 \mathrm{~mm}$.

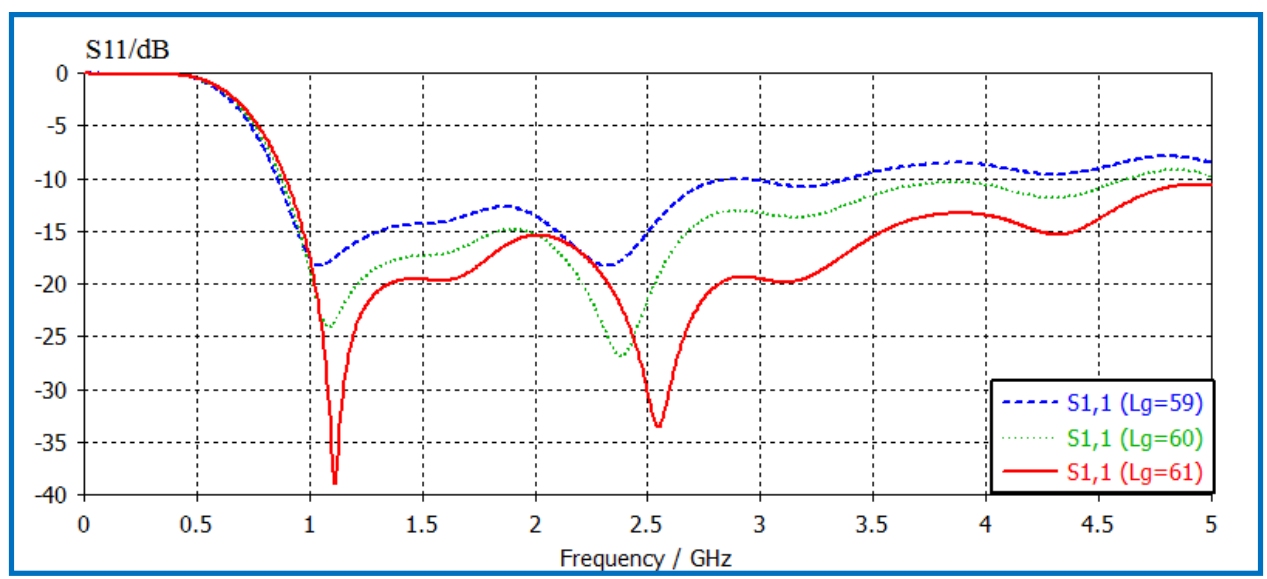

Figure 2. Simulation of $S_{11}$ versus frequency for different values of $\mathrm{Lg}$. 


\subsection{THE EFFECT OF GROUND PLAN WIDTH}

Figure (3) shows the S-parameter as a function of frequency for different values of ground plane width $\left(\mathrm{W}_{\mathrm{g}}\right)$, with fixing other parameter at $\mathrm{W}=61.5 \mathrm{~mm}, \mathrm{~L}=46.5 \mathrm{~mm}, \mathrm{~L}_{f}=62 \mathrm{~mm}, \mathrm{~W}_{\mathrm{f}}=2.5 \mathrm{~mm}, \mathrm{~L}_{g}=61 \mathrm{~mm}$. It can be seen the best value is $W_{g}=100 \mathrm{~mm}$, because minimum return loss and good bandwidth can be obtained at this value.

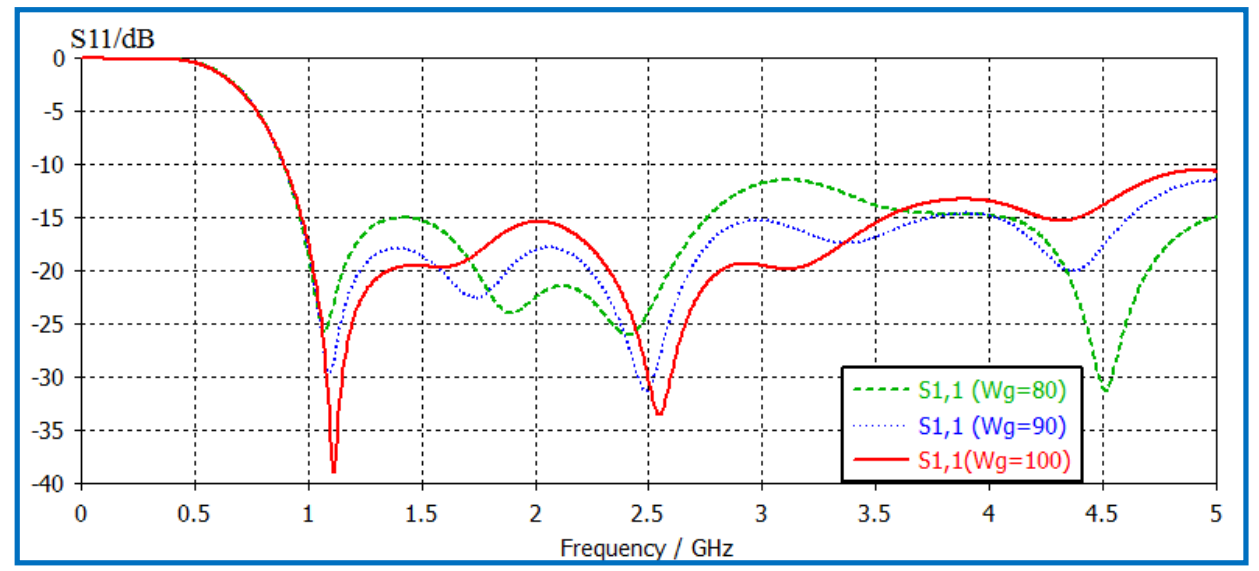

Figure 3. Simulation of $S_{11}$ versus frequency for different values of $W_{g}$.

\subsection{THE EFFECT OF FEEDER WIDTH}

Figure (4) presents S-parameter for different values of feeder width $\left(\mathrm{W}_{\mathrm{f}}\right)$, and fixing other parameters at $\mathrm{W}=61.5 \mathrm{~mm}, \mathrm{~L}=46.5 \mathrm{~mm}, \mathrm{~L}=62 \mathrm{~mm}, \mathrm{~L}_{\mathrm{g}}=61 \mathrm{~mm}, \mathrm{~W}_{\mathrm{g}}=100 \mathrm{~mm}$. The optimum value is $\mathrm{W}_{\mathrm{f}}=3$ because it gives minimum return loss at first resonance frequency and at second resonance frequency. First resonance frequency $f=1.06 \mathrm{GHz}$ has return loss equal to $-39.45 \mathrm{~dB}$, second resonance frequency $\mathrm{f}=2.4 \mathrm{GHz}$ has return loss equal to $-32.625 \mathrm{~dB}$.

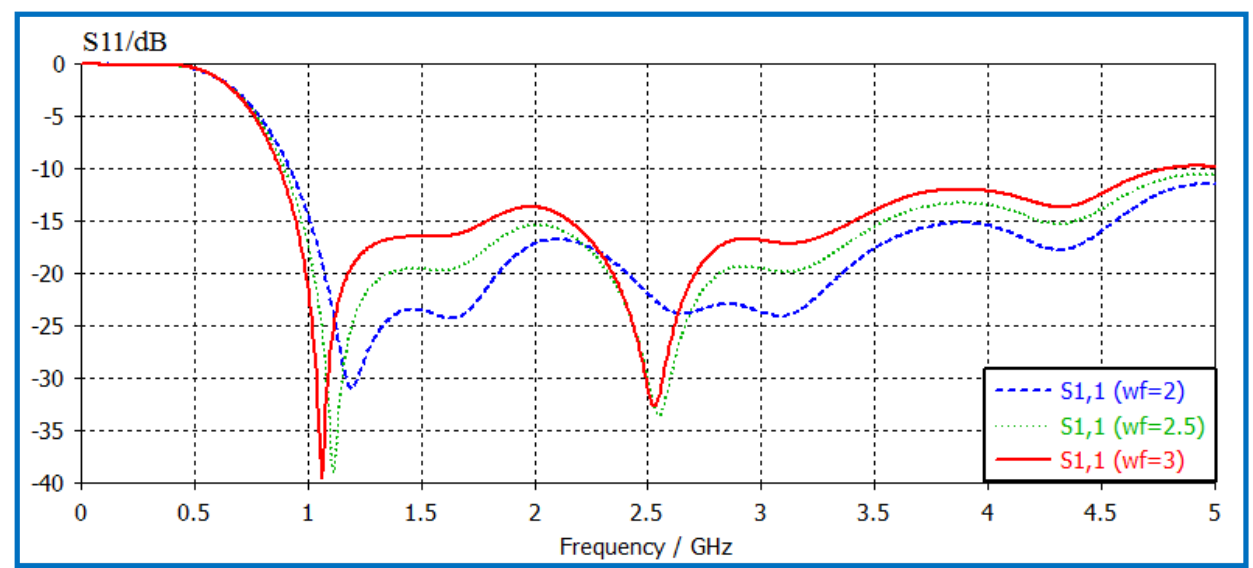

Figure 4. Simulation of $S_{11}$ versus frequency for different values of $W_{f}$. 


\subsection{THE EFFECT OF FEEDER LENGTH}

Figure (5) illustrates S-parameter of the proposed antenna by varying the length of the feeder $\left(\mathrm{L}_{f}\right)$, and fixing other values at $W_{f}=3 \mathrm{~mm}, W=61.5 \mathrm{~mm}, L=46.5 \mathrm{~mm}, L_{g}=61 \mathrm{~mm}, W_{g}=100 \mathrm{~mm}$. The optimum value of feeder lenght is $\mathrm{L}_{\mathrm{f}}=62.5 \mathrm{~mm}$, because it gives good impedance matching better than other values at same bandwidth.

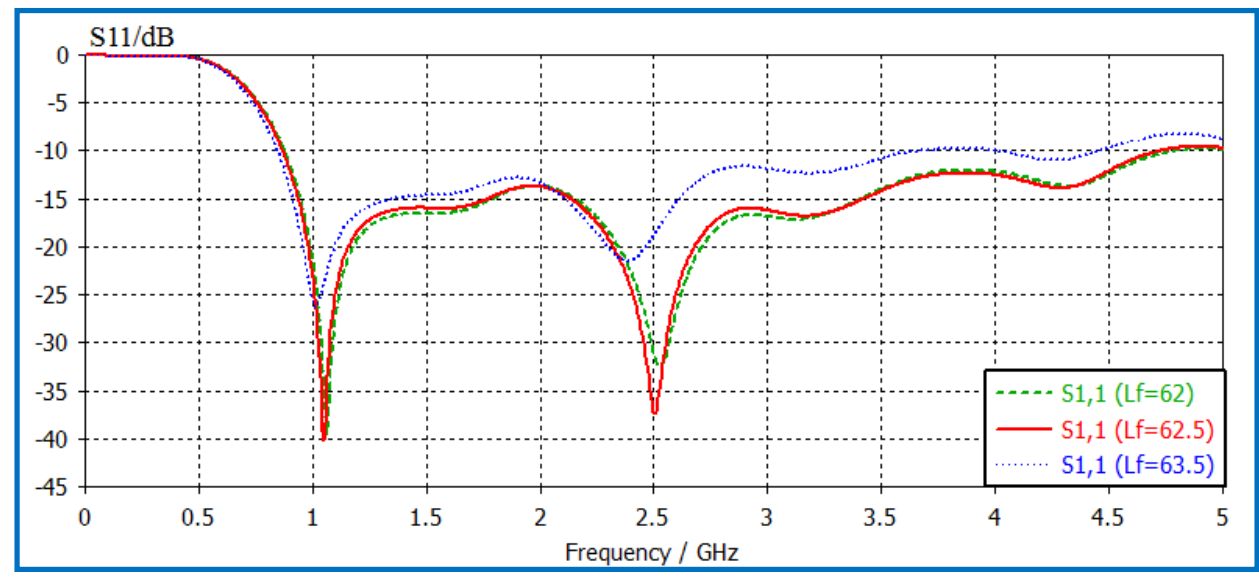

Figure 5. Simulation of $S_{11}$ versus frequency for different values of $L_{f}$.

The parameters of the optimized staircase patch are shown in Table 1.

Table 1. Optimal parameters of the staircase patch antenna.

\begin{tabular}{|l|l|l|}
\hline Parameter & Value & Description \\
\hline$L_{s}$ & $120 \mathrm{~mm}$ & Substrate length \\
\hline$W_{s}$ & $100 \mathrm{~mm}$ & Substrate width \\
\hline $\mathrm{Lf}_{f}$ & $62.5 \mathrm{~mm}$ & Feeder length \\
\hline$W_{f}$ & $3 \mathrm{~mm}$ & Feeder width \\
\hline $\mathrm{Lg}_{g}$ & $61 \mathrm{~mm}$ & Ground plan length \\
\hline $\mathrm{W}_{g}$ & $100 \mathrm{~mm}$ & Ground plan width \\
\hline $\mathrm{W}$ & $61.5 \mathrm{~mm}$ & Patch width \\
\hline $\mathrm{L}$ & $46.5 \mathrm{~mm}$ & Patch length \\
\hline $\mathrm{D}$ & $8.66 \mathrm{~mm}$ & The horizontal distance that is cut from the patch \\
\hline
\end{tabular}

The performance of the microstrip patch antenna can be further improved, by inserting multiple slots with different shapes and dimensions on the patch, because a slot is easy way to realize the redistribution of surface currents. Design procedure for inserting the slot is to choice the best position that has minimum current distribution along the patch, after that it can be used as the proper slot with initial parameters, by optimization process, it can be chosen to achieve the best values that enhance the antenna performance. Figure (6) shows the proposed staircase patch antenna with slots and the dimensions of each slot in the patch. 


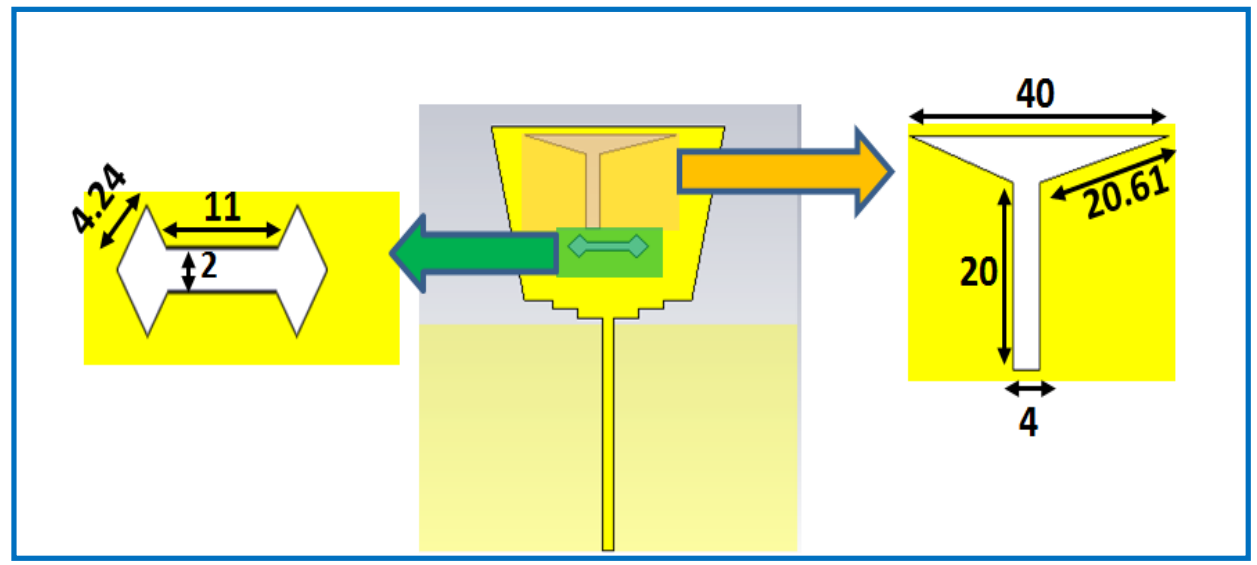

Figure 6. The proposed staircase patch antenna with slots.

Figure (7) shows the influence of slots on the return loss, it is observed that without the slot there exist two poorly matched resonances at $3.1 \mathrm{GHz}$ and $4.1 \mathrm{GHz}$. Introducing of multiple slots into the patch improve the input impedance matching, at $3.1 \mathrm{GHz}$ the return loss is improved from $-16 \mathrm{~dB}$ to $-39 \mathrm{~dB}$ and at $4.1 \mathrm{GHz}$ is improved from $-12 \mathrm{~dB}$ to $-16 \mathrm{~dB}$.

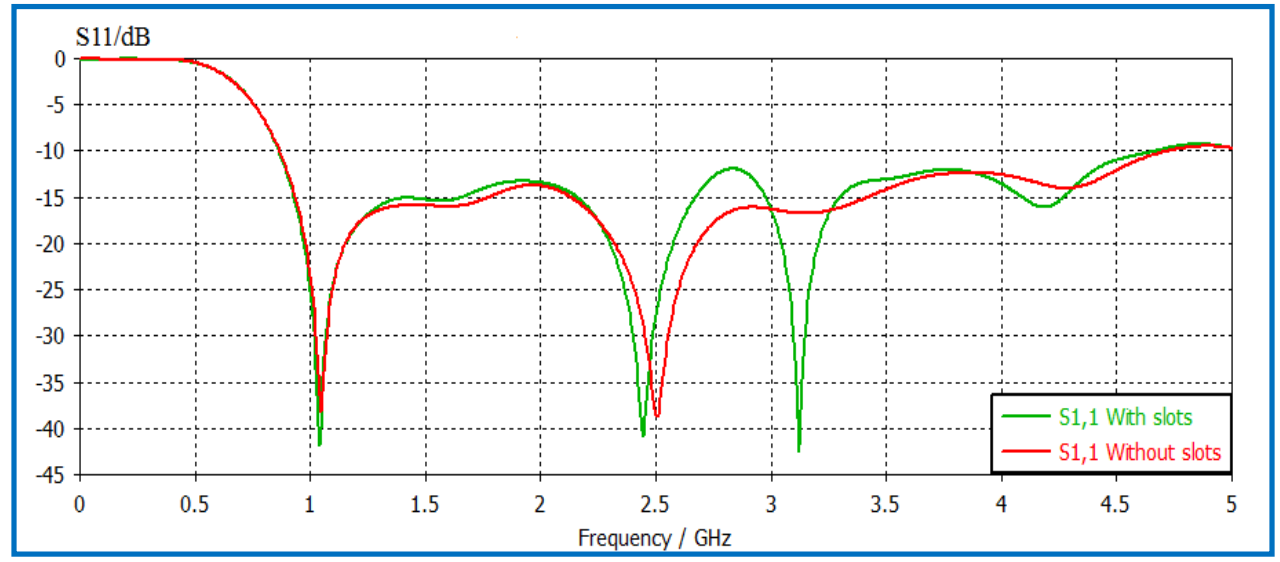

Figure 7. Simulation of $S_{11}$ versus frequency for the staircase patch with and without slots.

The proposed staircase patch antenna with slots is fabricated. Figure (8) shows the photograph of the fabricated antenna.

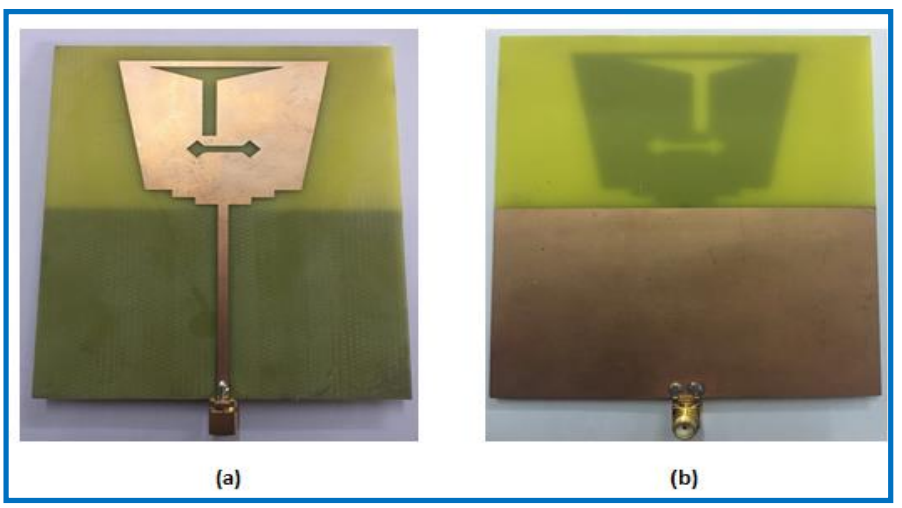

Figure 8. Photograph of the fabricated staircase patch antenna, (a) Front view, (b) Back view. 


\section{CHARACTERISTICS OF STAIRCASE PATCH ANTENNA WITH SLOTS}

\subsection{S-PARAMETER}

The fabricated staircase patch antenna is tested by using VNA (Vector Network Analyzer). Figure (9) shows the simulation and measurement S-parameter of the proposed antenna. Acceptable result between the measurement and simulation can be obtained, except from $3.5 \mathrm{GHz}$ to $3.88 \mathrm{GHz}$ became out of the proposed band. The variation in the measured and the simulated response is primarily due to fabrication errors, soldering of SMA connector or ambient environment which the measurement are carried out.

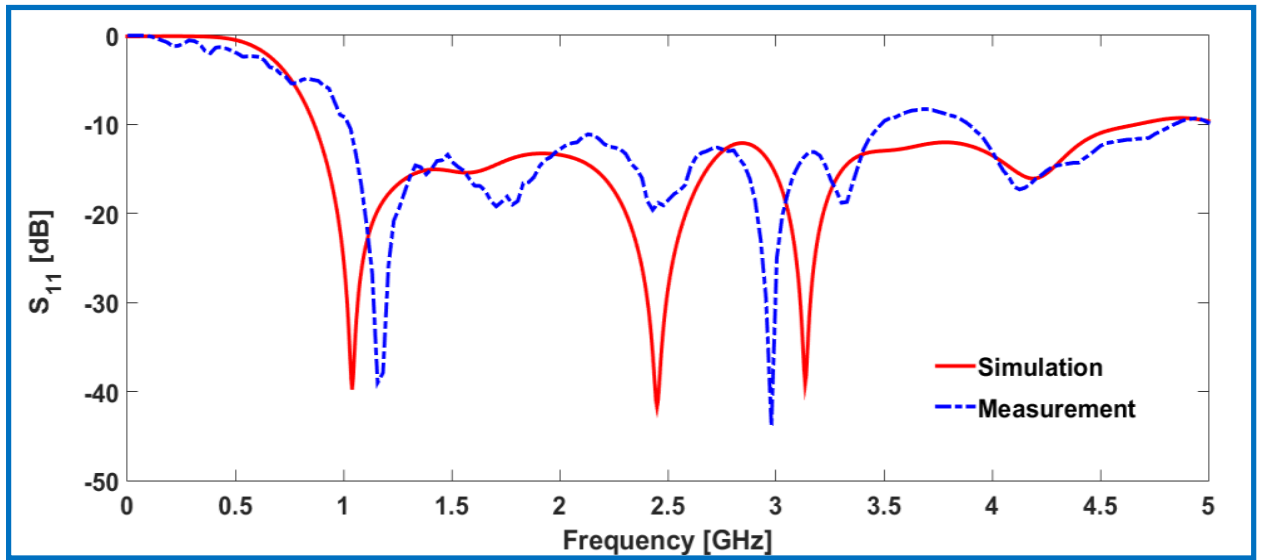

Figure 9. Simulation and measurement of S-Parameter for the staircase patch antenna with slots.

\subsection{VOLTAGE STANDING WAVE RATIO (VSWR)}

The antenna has smaller VSWR which means it is matched to the transmission line and can be considered the best antenna. The minimum VSWR is $1, \mathrm{VSWR}=1$ means no power reflected from the antenna, for practical applications VSWR less than or equal to 2 can be taken into account [8]. Figure (10) shows VSWR for different frequencies, it is clear that from the curve, the value of VSWR is less than 2 at all frequencies of the band and the best VSWR can be obtained at resonance frequencies, at $f=1 \mathrm{GHz} V S W R$ $=1.03$, at $\mathrm{f}=2.4 \mathrm{GHz}$ VSWR $=1.02$ and at $3.1 \mathrm{GHz}$ VSWR $=1$.

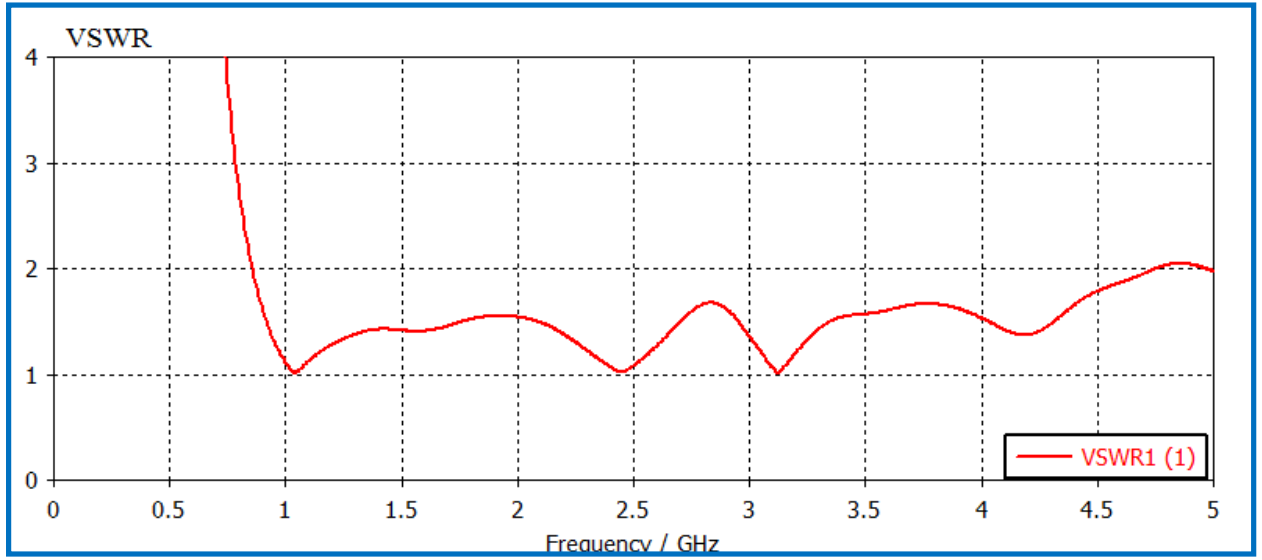

Figure 10. Simulation of VSWR versus frequency of staircase patch antenna with slots. 


\subsection{ANTENNA GAIN}

Figure (11) shows the effect of slots on the gain of the antenna, inserting slots to the patch also enhanced the gain of the antenna over a wide range of the frequencies. From 0.86 to $2 \mathrm{GHz}$ the gain didn't change, from $2 \mathrm{GHz}$ to $4.2 \mathrm{GHz}$ the gain improved significantly, but for frequency range from $4.3 \mathrm{GHz}$ to 4.8 $\mathrm{GHz}$ the gain slightly decreased.

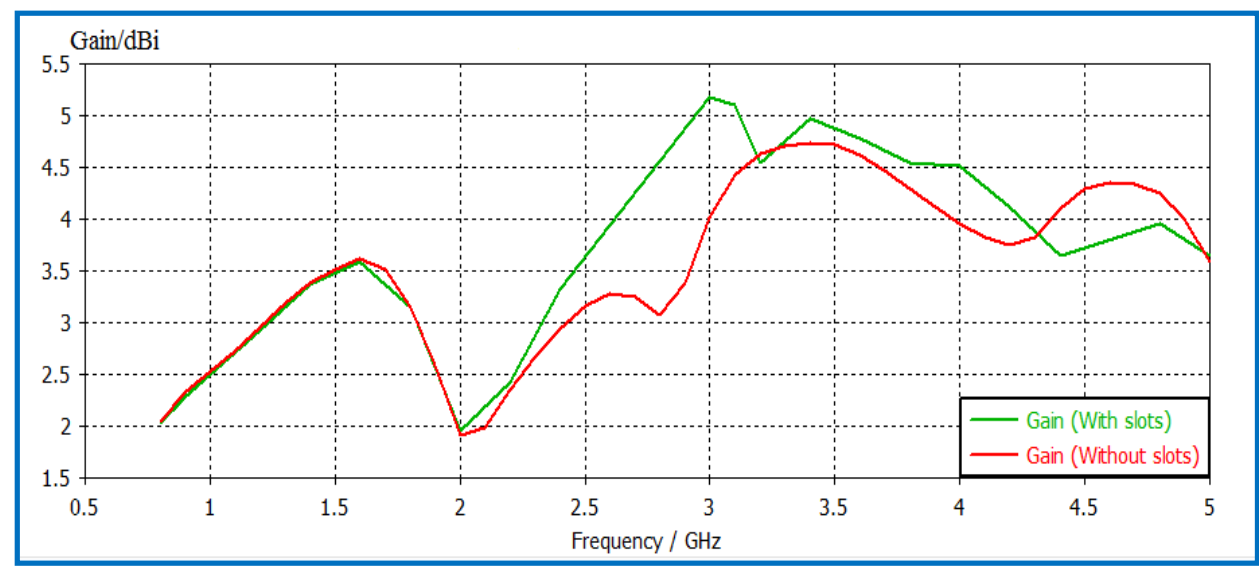

Figure 11. The gain of the staircase patch antenna with and without slots.

\subsection{INPUT IMPEDANCE}

From Figure (12), It can be observed that the relative impedance matching between the feed line and the antenna, and the real part of the impedance at resonance frequencies $(1 \mathrm{GHz}, 2.4 \mathrm{GHz}, 3.1 \mathrm{GHz})$ are $(48.9 \Omega, 47.5 \Omega, 48.15 \Omega)$ respectively, while imaginary part of the impedance at resonances frequencies are ($5.3 \Omega,-1.3 \Omega,-1.7 \Omega$ ) respectively.

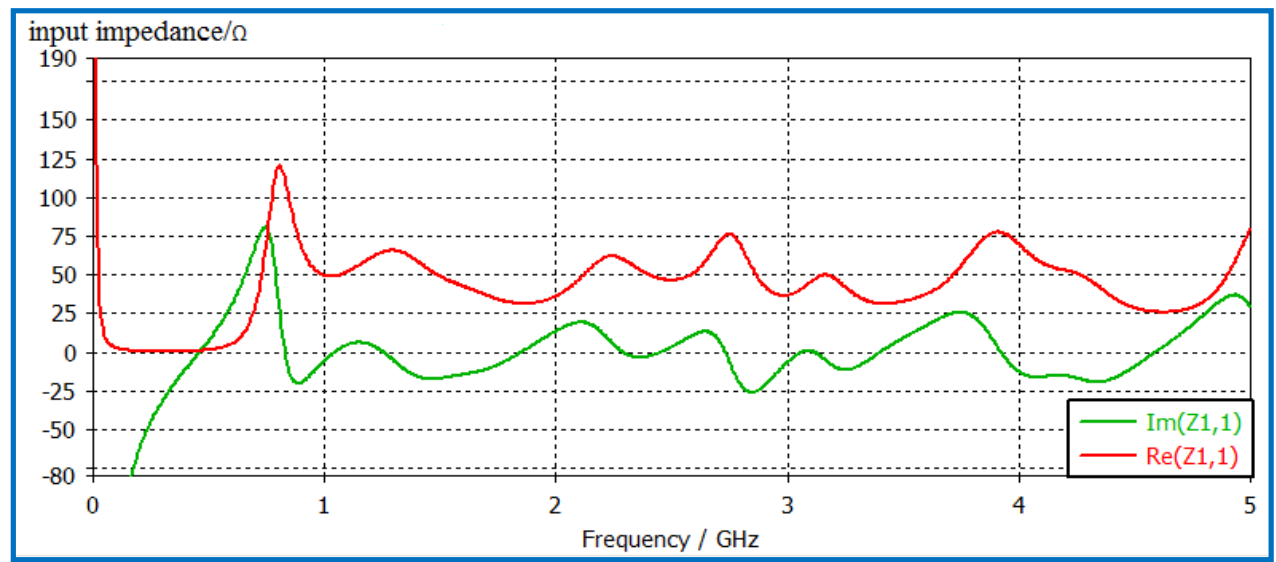

Figure 12. Real part and imaginary part of input impedance against frequencies for staircase patch antenna with slots 


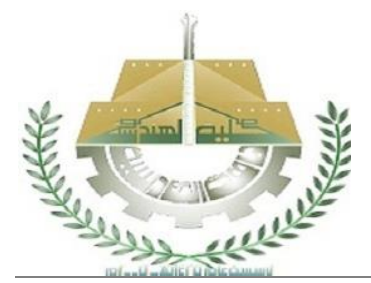

\section{JOURNAL OF AL-QADISIYAH FOR ENGINEERING SCIENCES}

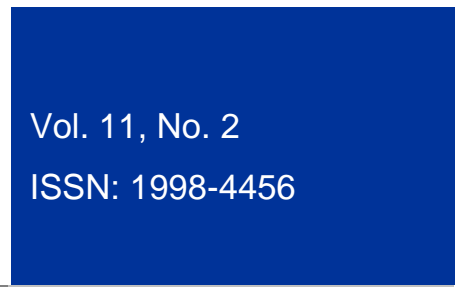

\subsection{CURRENT DISTRIBUTION}

The current distribution of the proposed staircase patch antenna with slots can be seen in Figure (13). Figure (13) offers the concentration of current in the antenna at frequencies $1 \mathrm{GHz}, 2.4 \mathrm{GHz}, 3.1 \mathrm{GHz}$ and 4 $\mathrm{GHz}$. Figure (13)a, shows the current distribution at the frequency $1 \mathrm{GHz}$, from the figure it can be noticed that the maximum current is $54.8 \mathrm{~A} / \mathrm{m}$ and most concentration of the current is on the feed line. Figure (13)b, shows the current distribution at frequency $2.4 \mathrm{GHz}$, from the figure it can be noticed that the maximum current equal to $66.1 \mathrm{~A} / \mathrm{m}$ and most concentration of the current on the feed line and around the sides of the upper slot. Figure (13)c, shows the current distribution at the frequency $3.1 \mathrm{GHz}$, from the figure it can be noticed that the maximum current is $163 \mathrm{~A} / \mathrm{m}$ and most concentration of the current around the sides of the upper slot. Figure (13)d shows the current distribution at the frequency $4 \mathrm{GHz}$, from the figure it can be noticed that the maximum current is $38.8 \mathrm{~A} / \mathrm{m}$ and most concentration of the current at most parts of the feed line and around the sides of the lower slot.

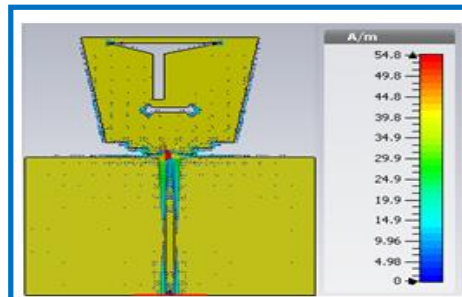

(a) $\mathrm{F}=1 \mathrm{GHz}$

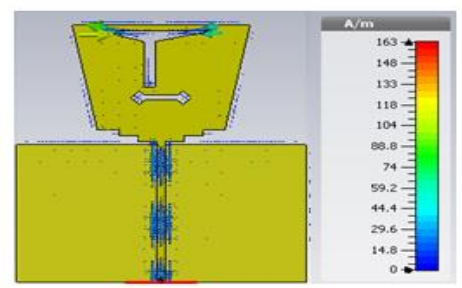

(c) $\mathrm{F}=3.1 \mathrm{GHz}$

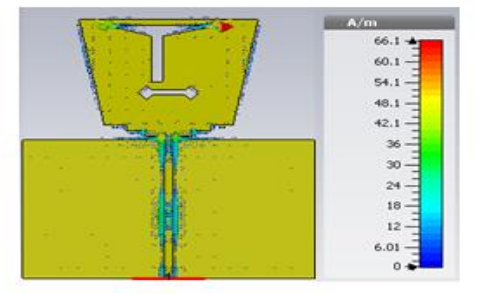

(b) $F=2.4 \mathrm{GHz}$

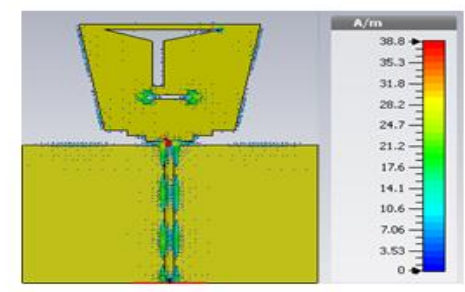

(d) $\mathrm{F}=4 \mathrm{G} \mathrm{Hz}$

Figure 13. The current distribution of the staircase patch antenna with slots at different frequencies.

\subsection{3-D RADIATION PATTERN}

The 3-D radiation pattern of the staircase patch at different frequencies is shown in Figure (14). The directivity over the phi and theta angels for the proposed antenna can be shown by these plots. For the frequencies $1 \mathrm{GHz}, 2.4 \mathrm{GHz}$ and $3.1 \mathrm{GHz}$, the maximum directivity is $2.59 \mathrm{dBi}, 3.69 \mathrm{dBi}$ and $5.96 \mathrm{dBi}$ respectively. The radiation pattern for frequencies $1 \mathrm{GHz}$ and $2.4 \mathrm{GHz}$ are omnidirectional radiation pattern and for $3.1 \mathrm{GHz}$ is quasi omnidirectional radiation pattern.

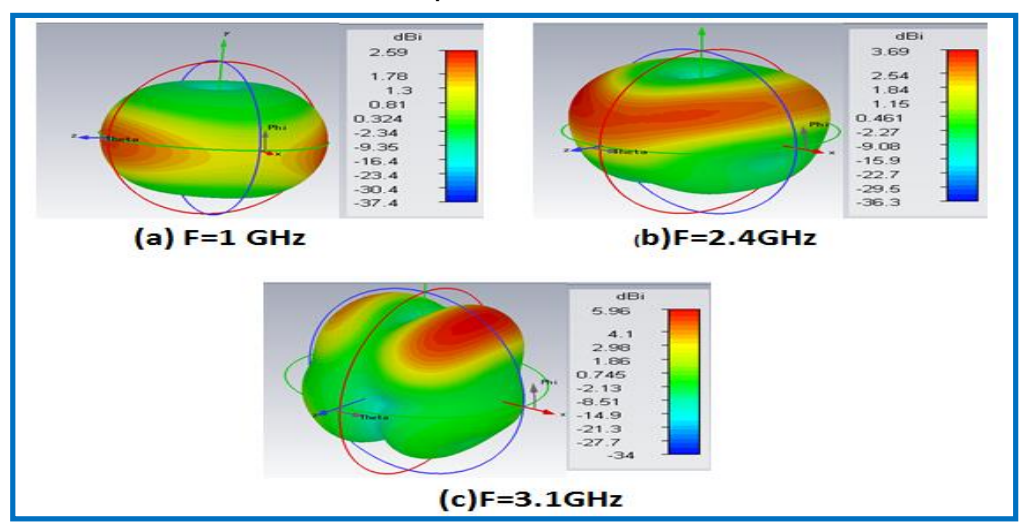

Figure 14. The 3-D radiation pattern of the antenna for different frequencies. 


\section{JOURNAL OF AL-QADISIYAH FOR ENGINEERING SCIENCES}

\subsection{E-PLANE, H-PLANE RADIATION PATTERN}

Figure (15) shows the E-plane and $\mathrm{H}$-plane for the frequencies $1 \mathrm{GHz}, 2.4 \mathrm{GHz}$ and $3.1 \mathrm{GHz}$. Figure (15) a shows $\mathrm{E}$-plane and $\mathrm{H}$-plane for $1 \mathrm{GHz}$, E-plane has main lobe magnitude equal to $2.59 \mathrm{dBi}$, main lobe direction is -176degree, angular width $(3 \mathrm{~dB})$ is 81.2 degree, $\mathrm{H}$-plane has main lobe magnitude equal to 1.26 $\mathrm{dBi}$, main lobe direction is -7 degree, angular width $(3 \mathrm{~dB})$ is 89 degree. Figure (15)b shows E-plane, H-plane for $2.4 \mathrm{GHz}$, E-plane has main lobe magnitude equal to $3.23 \mathrm{dBi}$, main lobe direction is -20degree, angular width $(3 \mathrm{~dB})$ is 66 degree, $\mathrm{H}$-plane has main lobe magnitude equal to $3.23 \mathrm{dBi}$, main lobe direction is 147 degree, angular width $(3 \mathrm{~dB})$ is 53 degree, side lobe level angular width (3dB) is $-7.6 \mathrm{~dB}$. Figure (15)c shows E-plane, $\mathrm{H}$-plane for $3.1 \mathrm{GHz}$, E-plane has main lobe magnitude equal to $-0.095 \mathrm{dBi}$, main lobe direction is 46 degree, angular width $(3 \mathrm{~dB})$ is 47 degree, side lobe level is $-1.3 \mathrm{~dB}$, $\mathrm{H}$-plane has main lobe magnitude equal to $5.99 \mathrm{dBi}$, main lobe direction is 57 degree, angular width $(3 \mathrm{~dB})$ is 37 degree, side lobe level is $-1.6 \mathrm{~dB}$.
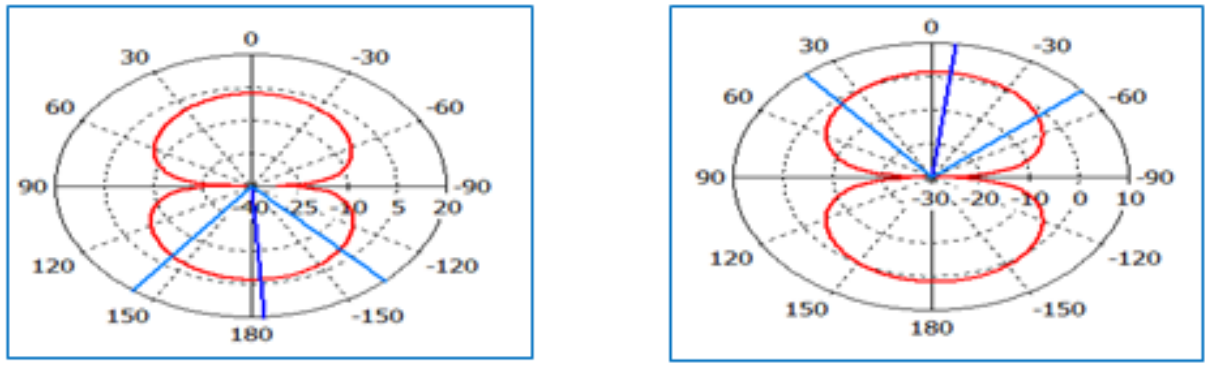

E-plane

(a) $\mathrm{F}=1 \mathrm{GHz}$

H-plane
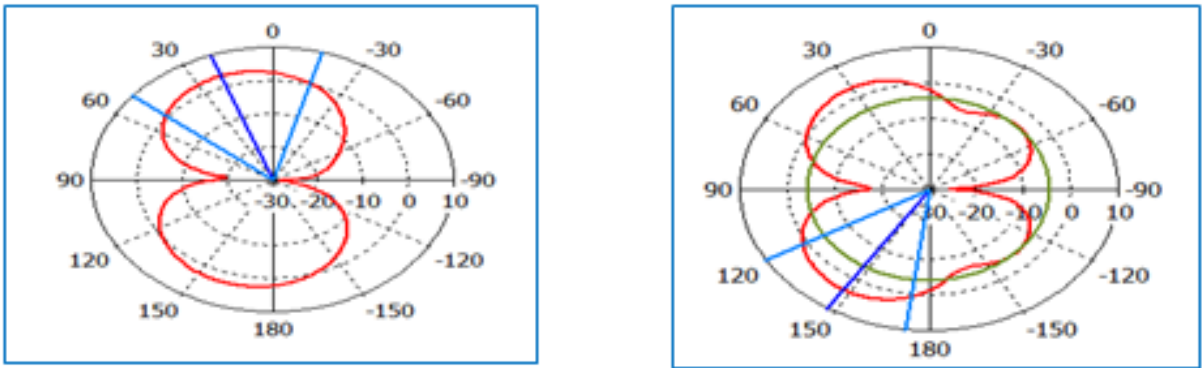

E-plane

(b) $\mathrm{F}=2.4 \mathrm{GHz}$

H-plane

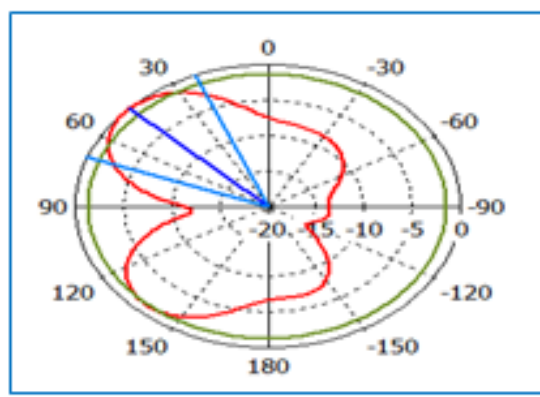

E-plane

(c) $\mathrm{F}=3.1 \mathrm{GHz}$

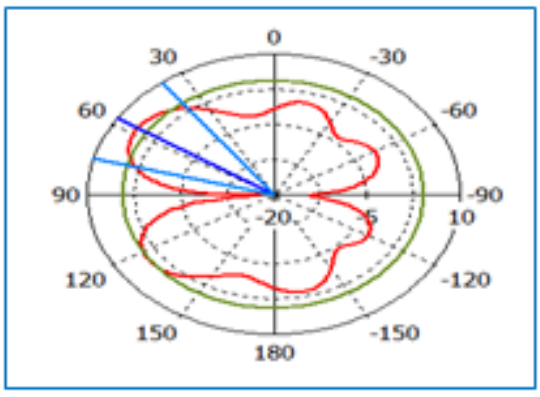

H-plane

Figure 15. E-Plane, H-Plane of staircase patch antenna with slots at different frequencies. 


\subsection{GROUP DELAY}

The group delay of staircase patch antenna with slots is shown in the Figure (16). It can be observed that group delay is less than $2 \mathrm{~ns}$ in the most of the band, which means minimum distortion occurs on the pulse, because the group delay is constant in almost all the ranges of frequencies.

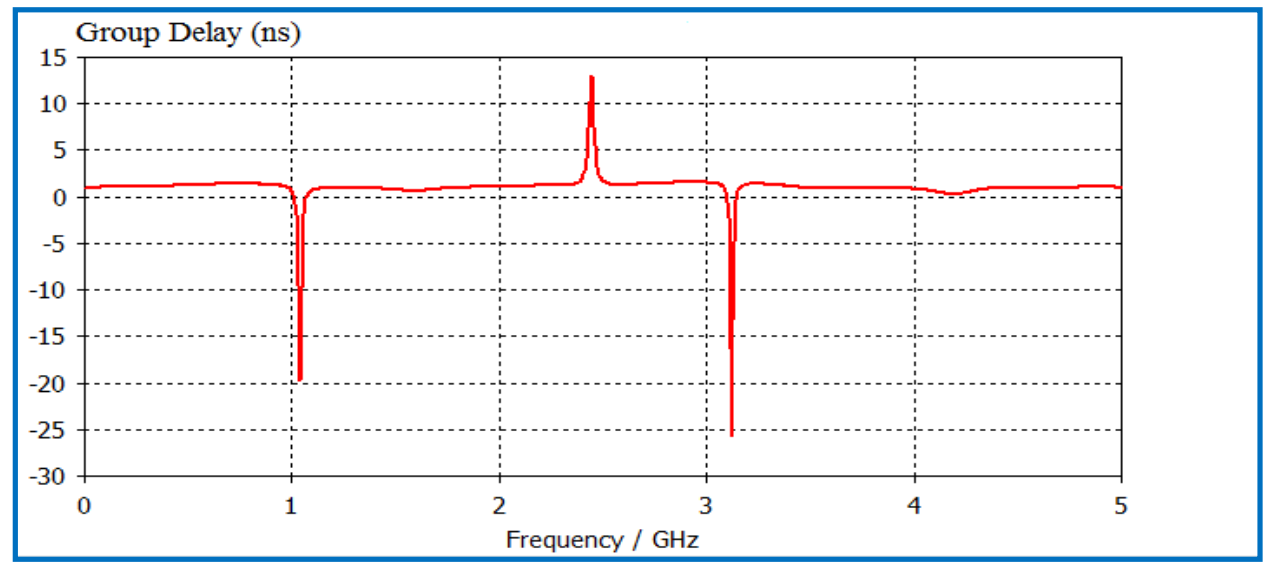

Figure 16. The group delay versus frequency for staircase patch antenna with slots.

Table 2 which is shown below, illustrates a survey comparison between this work and the work in the reference [9]. From Table 2, it can be noticed that the antenna in the reference [9] covers three separated band, but this work covers a wider bandwidth equal to $3.92 \mathrm{GHz}$, with acceptable gain ranging from $2.18 \mathrm{dBi}$ to $5.3 \mathrm{dBi}$, and also can be made a size reduction of the antenna by $42.86 \%$ as compared to the antenna in reference [9].

Table 2. Comparision between this work and work in the reference [9].

\begin{tabular}{|l|l|l|l|}
\hline Refrences & Bandwidth $(\mathrm{GHz})$ & Gain $(\mathrm{dBi})$ & Dimensions $(\mathrm{W} \times \mathbf{L} \times \mathrm{H}) \mathrm{mm}^{3}$ \\
\hline Ref [9] & $\begin{array}{l}(0.68-0.821) \&(0.86-0.96) \\
(1.56-2.15) \&(2.13-2.495)\end{array}$ & $(0.89-2.47)$ & $(230 \times 176 \times 0.8)$ \\
\hline This work & $(0.86-4.87)$ & $(2.18-5.3)$ & $(100 \times 120 \times 1.542)$ \\
\hline
\end{tabular}

\section{CONCLUSION}

A staircase broadband microstrip patch antenna operates in the $2 \mathrm{G} / 3 \mathrm{G} / 4 \mathrm{G}$ mobile base station has been proposed. The key of the design is the use of a stepped patch to enhance the matching between the antenna and the transmission line. The proposed antenna operates in the frequency range from $0.86 \mathrm{GHz}$ to $4.78 \mathrm{GHz}$, and gives gain ranging from $2.18 \mathrm{dBi}$ to $5.3 \mathrm{dBi}$. The antenna is designed using multiple slots configuration, with optimization techniques implemented on it to achieve the best possible desired results. The proposed antenna with slots is fabricated and tested practically using MS46-42A Vector Network 
Analyzer (VNA), and the result of $\mathrm{S} 11$ is compared with simulation result, it is observed that the practical result agree with simulation result and a slight difference is attributed to the fabrication errors.

\section{REFERENCES}

1. M.S.El, gendy; H.H., Abdullah, E.A.; gendy, E.A, Abdallah, Mobile Base Station Dual Band Microstrip Antenna, Electronics Research Institute, Dokki, Giza, Egypt, 2014 IEEE.

2. C. A., Balanis, Antenna Theory Analysis and Design, Third Edition, 2005.

3. Y., Entiefa Mansour, Single Slot Dual Band Microstrip Antenna for WIMAX Application, Atilim University, thesis 2014.

4. Ankur Kaushal; Sachin Tyagi, Microstrip patch antenna, its types, merits demerits and its applications, "international journal of engineering sciences \& research technology, 2015.

5. Ahmed Fatthi Alsager, Design and Analysis of Microstrip Patch Antenna Arrays, Electrical EngineeringCommunication and Signal processing, College of Borås, 2011.

6. Sven Erik Sandström; Muhammad Ishfaq ; Raja Sheharyar khan, A compact Microstrip Patch Antenna for LTE Applications, School of Computer Science, Physics and Mathematics 2013.

7. Amit Das; Prof., Asish Dubey, Broad Band Microstrip Patch Antenna Design- A Critical review, International Research Journal of Engineering and Technology (IRJET), 2017.

8. Dhanraj Meena; R.S., Meena, Triple Band U-Slot Microstrip Patch Antenna for WLAN and Wireless Sensor Applications, International Conference on Communication, Control and Intelligent Systems (CCIS) 2015.

9. Sultan Shoaib; Imran Shoiab; Nosherwan Shoaib, Compact and printed MIMO Antennas for 2G/3G and 4G-LTE Mobile Tablets, IEEE 2015. 